Louisiana State University

LSU Digital Commons

Faculty Publications

Department of Chemistry

$5-1-2005$

\title{
Studies on the subcellular localization of the porphycene CPO
}

David Kessel

Wayne State University School of Medicine

Mary Conley

Wayne State University

M. Graça H. Vicente

Louisiana State University

John J. Reiners

Wayne State University

Follow this and additional works at: https://digitalcommons.Isu.edu/chemistry_pubs

\section{Recommended Citation}

Kessel, D., Conley, M., Vicente, M., \& Reiners, J. (2005). Studies on the subcellular localization of the porphycene CPO. Photochemistry and Photobiology, 81 (3), 569-572. https://doi.org/10.1562/ 2004-12-16-RA-403.1

This Conference Proceeding is brought to you for free and open access by the Department of Chemistry at LSU Digital Commons. It has been accepted for inclusion in Faculty Publications by an authorized administrator of LSU Digital Commons. For more information, please contact ir@lsu.edu. 


\title{
Studies on the Subcellular Localization of the Porphycene CPOI
}

\author{
David Kessel ${ }^{1,{ }^{*}, \text { Mary Conley }^{2} \text {, M. Graça H. Vicente }}{ }^{3}$, and John J. Reiners Jr. ${ }^{4}$ \\ ${ }^{1}$ Department of Pharmacology, Wayne State University School of Medicine, Detroit, MI \\ ${ }^{2}$ Cancer Biology Program, Wayne State University, Detroit, MI \\ ${ }^{3}$ Department of Chemistry, Louisiana State University, Baton Rouge, LA \\ ${ }^{4}$ Institute of Environmental Health Sciences, Wayne State University, Detroit, MI
}

\begin{abstract}
This study was designed to provide more detailed information on the subcellular sites of binding of the porphycene, termed 9-capronyloxytetrakis (methoxyethyl) porphycene (CPO), with a fluorescence resonance energy transfer (FRET) technique. The proximity of CPO to two fluorescent probes was determined: nonyl acridine orange (NAO), a dye with specific affinity for the mitochondrial lipid cardiolipin, and dihexaoxacarbocyanine iodide $\left(\mathrm{DiOC}_{6}\right)$, an agent that labels the endoplasmic reticulum (ER). FRET spectra indicated energy transfer between $\mathrm{DiOC}_{6}$ and $\mathrm{CPO}$ but no significant transfer between $\mathrm{NAO}$ and $\mathrm{CPO}$. These results confirm data obtained by fluorescence microscopy, suggesting a similar pattern of subcellular localization by $\mathrm{CPO}$ and $\mathrm{DiOC}_{6}$ but not by $\mathrm{CPO}$ and NAO. However, when cells containing $\mathrm{CPO}$ were irradiated and then loaded with NAO, FRET between the two fluorophores was observed. Hence, a relocalization of CPO can occur during irradiation. These data provide an explanation for recent studies on CPO-catalyzed photodamage to both ER and mitochondrial Bcl-2.
\end{abstract}

\section{INTRODUCTION}

In a recent report (1), we examined sites of photodamage in murine leukemia L1210 cells using the porphycene termed 9-capronyloxytetrakis (methoxyethyl) porphycene (CPO) $(2,3)$ as the photosensitizing agent. Colocalization studies indicated that $\mathrm{CPO}$ was predominantly localized in the endoplasmic reticulum (ER). Moreover, Bcl-2 associated with the ER was a target for photodamage. At an increased light dose, however, we also observed photodamage to mitochondrial Bcl-2. One explanation is that a minor fraction of CPO was bound to mitochondria, but the degree of binding was insufficient for detection by fluorescence microscopy. Another possibility is that $\mathrm{CPO}$ relocalized during irradiation.

In this study, we used fluorescence resonance energy transfer (FRET) techniques to examine the proximity of CPO to two fluorescent probes, 3,3'-dihexyloxacarbocyanine iodide $\left(\mathrm{DiOC}_{6}\right)$ and nonyl acridine orange (NAO), which are commonly used in fluorescence microscopy to identify the ER and mitochondria, respectively $(4,5)$. The data obtained are consistent with $\mathrm{CPO}$ being initially associated with the ER but, during subsequent irradiation, some relocalization to the mitochondria occurs, rendering that organelle sensitive to photodamage.

\footnotetext{
IIPosted on the website on 3 March 2005

(C) 2005 American Society for Photobiology

*To whom correspondence should be addressed: Department of Pharmacology, Wayne State University School of Medicine, Detroit, MI 48201, USA.dhkessel@med.wayne.edu.
} 


\section{MATERIALS AND METHODS}

\section{Synthetic procedures}

CPO was prepared essentially as described by Richert et al. (2) with minor modifications. Characterization of intermediates was in agreement with data provided in this reference.

\section{Cell culture procedures}

Murine L1210 cells were maintained in suspension culture in an approximation of Fisher's growth medium. This was obtained by supplementing $\alpha$-MEM (GIBCO-BRL, Grand Island, $\mathrm{NY}$ ) with $\mathrm{MgCl}_{2}(45 \mathrm{mg} / \mathrm{L})$, methionine $(75 \mathrm{mg} / \mathrm{L})$, phenylalanine $(30 \mathrm{mg} / \mathrm{L})$, valine $(30 \mathrm{mg} /$ $\mathrm{L})$ and folic acid $(9 \mathrm{mg} / \mathrm{L})$. Additional components were $10 \%$ horse serum, $1 \mathrm{mM}$ glutathione, $1 \mathrm{mM}$ mercaptoethanol and gentamicin.

\section{Spectral studies}

The absorbance spectrum of CPO was acquired in ethanolic solution with a Shimadzu BioSpec model 1602 dual-beam spectrophotometer. Fluorescence excitation and emission spectra of $\mathrm{CPO}, \mathrm{NAO}$ and $\mathrm{DiOC}_{6}$ were obtained with an SLM 48000 fluorometer as modified by ISS (Champaign, IL). To obtain complete emission spectra of $\mathrm{NAO}$ and $\mathrm{DiOC}_{6}$, excitation at 488 $\mathrm{nm}$ was employed. Excitation spectra were obtained with $540 \mathrm{~nm}$ emission. All FRET studies involved excitation at $488 \mathrm{~nm}$ (bandwidth $=\mathrm{nm}$ ). This wavelength does not elicit $\mathrm{CPO}$ fluorescence, so any long-wavelength emission from cells containing $\mathrm{CPO}+\mathrm{NAO}$ or $\mathrm{DiOC}_{6}$ could arise only from an energy transfer phenomenon. The $\mathrm{CPO}$ fluorescence emission at $650 \mathrm{~nm}$ was determined with $550 \mathrm{~nm}$ excitation, whereas the excitation spectrum in the vicinity of $550 \mathrm{~nm}$ was determined with $650 \mathrm{~nm}$ emission.

\section{Fluorescence microscopy}

Fluorescence images were acquired with a SenSys CCD camera (Photometrics, Tucson, AZ) fit with a Uniblitz shutter (Vincent Associates, Rochester, NY) and MetaMorph software (Universal Imaging, Downingtown, PA). All studies were carried out on live cells with a microscope stage thermoelectrically cooled to $15^{\circ} \mathrm{C}$ to prevent metabolic changes during image acquisition. CPO was excited at 350-450 nm with fluorescence detected at wavelengths $>600$ $\mathrm{nm} ; \mathrm{NAO}$ and $\mathrm{DiOC}_{6}$ were excited at $450-490 \mathrm{~nm}$ with fluorescence detected at $515-535 \mathrm{~nm}$. To minimize photobleaching the Uniblitz shutter was configured to open and close with the camera shutter, limiting exposure of the samples to exciting light for $<300 \mathrm{~ms}$.

\section{FRET acquisition}

L1210 cells $\left(7 \mathrm{mg} / \mathrm{mL}, 2 \times 10^{6}\right.$ cells $\left./ \mathrm{mL}\right)$ in FHS medium (Fischer's medium containing $10 \%$ horse serum with the $\mathrm{NaHCO}_{3}$ replaced by $10 \mathrm{~m} M$ HEPES buffer, $\mathrm{pH}$ 7.4) were singly incubated with $2 \mu \mathrm{M} \mathrm{CPO}, 300 \mathrm{nM}$ NAO or $800 \mathrm{nM} \mathrm{DiOC}_{6}$ or with combinations of CPO + $\mathrm{NAO}$ and $\mathrm{CPO}+\mathrm{DiOC}_{6}$. The procedure involved incubation with $\mathrm{CPO}$ for $30 \mathrm{~min}$ at $37^{\circ} \mathrm{C}$, with the fluorescent probe added for the final $5 \mathrm{~min}$. When cells were labeled with only the probes, total incubation time was $5 \mathrm{~min}$. The cells were washed with $0.9 \% \mathrm{NaCl}$ and suspended in a modified FHS buffer at $15^{\circ} \mathrm{C}$. This formulation lacked the serum, vitamins and amino acids present in the growth medium. The final density was $7 \times 10^{5}$ cells $/ \mathrm{mL}$. Fluorescence emission spectra showing FRET were acquired with $488 \pm 2 \mathrm{~nm}$ excitation. In another series of studies, cells were loaded with $2 \mu \mathrm{M} \mathrm{CPO}$ for $30 \mathrm{~min}$ at $37^{\circ} \mathrm{C}$, washed and resuspended in fresh medium at $10^{\circ} \mathrm{C}$ and irradiated at a light dose of $180 \mathrm{~mJ} / \mathrm{cm}^{2}$. This corresponds to the conditions that elicit loss of both ER and mitochondrial Bcl-2 (1). The fluorescent probes were added after irradiation, and the cells were then used for FRET analysis carried out at $15^{\circ} \mathrm{C}$. 
The light source was a 700 watt quartz-halogen lamp filtered with $10 \mathrm{~cm}$ of water to remove excess infrared radiation. The transmission wavelength was confined to 550-700 nm with band-pass filters (Oriel, Stratford, CT) corresponding to the three CPO Q-bands (Fig. 1).

\section{RESULTS AND DISCUSSION}

\section{Absorbance spectra}

The absorbance spectrum of CPO is shown in Fig. 1. A soret band at $369 \mathrm{~nm}$ was detected along with Q bands at 560, 603 and $632 \mathrm{~nm}$. The appearance of an absorbance band in the green indicated that FRET between $\mathrm{CPO}$ and fluorescence probes for specific organelles was feasible because both $\mathrm{DiOC}_{6}$ and $\mathrm{NAO}$ have fluorescence emission bands in this region of the spectrum.

\section{Fluorescence excitation and emission spectra}

NAO showed an excitation optimum of $501 \mathrm{~nm}$ with an emission peak at $518 \mathrm{~nm}$ (Fig. 2A). DiOC $_{6}$ exhibited excitation and emission optima at 490 and $501 \mathrm{~nm}$, respectively (Fig. 2B). In contrast, the excitation and emission optima of $\mathrm{CPO}$ at 563 and $644 \mathrm{~nm}$, respectively, were markedly different from those of $\mathrm{NAO}$ or $\mathrm{DiOC}_{6}$ (compare Fig. $2 \mathrm{C}$ with $\mathrm{A}$ and $\mathrm{B}$ ). In principal, because the emission spectra of both $\mathrm{NAO}$ and $\mathrm{DiOC}_{6}$ overlapped with the excitation spectrum of $\mathrm{CPO}$, FRET should be observed with the $\mathrm{NAO} / \mathrm{CPO}$ and $\mathrm{DiOC}_{6} / \mathrm{CPO}$ pairs, providing the two agents are in sufficiently close proximity.

\section{Fluorescence microscopy}

Fluorescence microscopy demonstrated that CPO and NAO did not colocalize in L1210 cells (compare Fig. $3 \mathrm{~A}$ with $\mathrm{B}$ ). In contrast, there was a pronounced colocalization of $\mathrm{CPO}$ with the ER probe $\mathrm{DiOC}_{6}$ (compare patterns in Fig. $3 \mathrm{C}$ with $\mathrm{D}$ ). Additional images were acquired after cells were loaded with $\mathrm{CPO}$ and irradiated. The $\mathrm{CPO}$ signal became somewhat more diffuse after irradiation, but there were no significant changes in the $\mathrm{DiOC}_{6}$ and $\mathrm{NAO}$ images.

\section{FRET analysis}

Irradiation of cells containing CPO at $488 \mathrm{~nm}$ yielded no detectable fluorescence (Fig. 4A, trace A). This wavelength was therefore appropriate for FRET studies because fluorescence excitation of $\mathrm{NAO}$ or $\mathrm{DiOC}_{6}$ could occur without eliciting any response from $\mathrm{CPO}$ in the absence of FRET.

A faint fluorescence signal was obtained at wavelengths above $620 \mathrm{~nm}$ when cells containing only $\mathrm{DiOC}_{6}$ were excited at $488 \mathrm{~nm}$ (Fig. 4A, trace B). A greater signal, indicative of FRET, was obtained when both $\mathrm{DiOC}_{6}$ and $\mathrm{CPO}$ were present during excitation (Fig. $4 \mathrm{~A}$, trace $\mathrm{C}$ ). In an inset to Fig. 4A, we show the FRET signal from $\mathrm{DiOC}_{6}+\mathrm{CPO}$ before (solid line) and after (dashed line) irradiation. In the latter study, the probe was added after irradiation to avoid possible artifacts caused by $\mathrm{DiOC}_{6}$ photooxidation. No significant change was observed, indicating that the proximity of $\mathrm{CPO}$ and the fluorescent probe were not altered by irradiation.

When cells contained only NAO, excitation at $488 \mathrm{~nm}$ resulted in a weak fluorescence emission signal at wavelengths $>620 \mathrm{~nm}$ (Fig. 4B, trace A). This signal was not significantly affected when $\mathrm{CPO}$ was also present (Fig. 4B, trace B). Hence, there was essentially no FRET in cells that had been coloaded with $\mathrm{NAO}$ and $\mathrm{CPO}$. This situation changed if cultures were first loaded with CPO and irradiated at 550-700 $\mathrm{nm}$, resulting in a photodynamic therapy (PDT) effect, then treated with $\mathrm{NAO}$ and excited at $488 \mathrm{~nm}$ to specifically excite NAO. In such a protocol, FRET between NAO and CPO occurred, and an enhanced CPO emission signal was seen at $\sim 650 \mathrm{~nm}$ (Fig. 4B, trace C). 
It is common to note a decrease in donor fluorescence when FRET occurs. In these experiments, the magnitude of the $\mathrm{NAO}$ and $\mathrm{DiOC}_{6}$ fluorescence was much greater than the FRET signal, so it was difficult to distinguish this effect. An inset in Fig. 4B shows the NAO signal before and after irradiation. No significant alteration in the fluorescence emission spectrum was detected after irradiation.

\section{CONCLUSIONS}

On the basis of the $\mathrm{CPO}$ absorbance spectrum (Fig. 1) and the fluorescence excitation spectra of NAO and $\mathrm{DiOC}_{6}$ (Fig. 2), we determined that FRET could be used to obtain information on the proximity of the photosensitizer $\mathrm{CPO}$ to $\mathrm{NAO}$ and $\mathrm{DiOC}_{6}$, two fluorescent probes useful for subcellular localization. The latter dye was initially developed as a fluorescent label for the ER (4), whereas NAO is a specific probe for cardiolipin, a lipid found only in the mitochondrial inner membrane (5). NAO had previously been used in a FRET study that identified mitochondrial cardiolipin as a site of binding of the phthalocyanine photosensitizer Pc 4 (6). In this study, we have not carried out calculations on probable distances between CPO and the fluorescence probes as was done by Oleinick's group (6) because some of the required parameters are unknown.

Results from fluorescence microscopy described here (Fig. 3) and elsewhere (1) suggested that the porphycene CPO is initially bound to the ER. Because these data are only qualitative, it is difficult to assign definitive localization patterns solely on the basis of such studies. This study demonstrates the potential value of FRET for delineating colocalization phenomena in which fluorescence microscopy is insufficiently sensitive. The small cytoplasmic compartment of L1210 cells causes considerable overlap between cellular organelles confined to that region. We have now shown that FRET between CPO and the mitochondrial probe NAO was essentially undetectable, whereas FRET between $\mathrm{CPO}$ and the ER probe $\mathrm{DiOC}_{6}$ was readily apparent (Fig. 4A). These data enable us to provide a more definitive indication of subcellular CPO binding sites.

On irradiation of CPO-sensitized L1210 cells, loss of Bcl-2 from both the ER and mitochondria was observed, although the effect was greatest for Bcl-2 located in the ER (1). One possible explanation for this result is the partial relocalization of CPO during irradiation, with mitochondria being among the new sites of affinity. Although DiOC $_{6}$ can also label mitochondria (7), the lack of FRET between NAO and CPO indicates that the FRET signal obtained with $\mathrm{DiOC}_{6}$ solely derives from the ER localization of this probe.

In this study, we show that CPO did not have sufficient affinity to mitochondria to elicit FRET with the cardiolpin probe NAO, but energy transfer was observed after PDT (Fig. 4B).

Relocalization of photosensitizing agents during irradiation has been reported before. Moan's group (8) described a PDT-induced movement of a photosensitizing agent from lysosomes to the cytosol, and we provided another example involving the migration of a cationic sensitizer from the plasma membrane to cytosolic proteins during irradiation (9). This study documents a third such example. It appears that the initial site(s) of binding of a photosensitizer might be only one determinant of the ultimate loci of subcellular photodamage.

\section{Abbreviations}

$\begin{array}{ll}\text { CPO } & \text { 9-capronyloxytetrakis (methoxyethyl) porphycene } \\ \text { DiOC }_{6} & \text { 3,3'-dihexyloxacarbocyanine iodide } \\ \text { ER } & \text { endoplasmic reticulum }\end{array}$


FHS Fischer's medium containing $10 \%$ horse serum with the $\mathrm{NaHCO}_{3}$ replaced by 10 mM HEPES buffer $\mathrm{pH} 7.4$

FRET fluorescence resonance energy transfer

NAO nonyl acridine orange

PDT photodynamic therapy

\section{Acknowledgments}

This work was supported by grants CA 92618 and CA 23378 from the National Institutes of Health. We thank Ann Marie Santiago and Nakaiya Adjeley Okan-Mensah for excellent technical assistance.

\section{REFERENCES}

1. Kessel D, Castelli M, Reiners JJ Jr. Ruthenium red-mediated suppression of Bcl-2 loss and $\mathrm{Ca}^{2+}$ release initiated by photodamage to the endoplasmic reticulum: scavenging of reactive oxygen species. Cell Death Differ. 2005 doi: 10.1038/sj.cdd.4401579.

2. Richert C, Wessels JM, Muller M, Kisters M, Benninghaus T, Goetz AE. Photodynamic antitumor agents: beta-methoxyethyl groups give access to functionalized porphycenes and enhance cellular uptake and activity. J. Med. Chem 1994;37:2797-2807. [PubMed: 8064807]

3. Toledano H, Edrei R, Kimel S. Photodynamic damage by liposome-bound porphycenes: comparison between in vitro and in vivo models. J. Photochem. Photobiol. B 1998;42:20-27. [PubMed: 9491592]

4. Terasaki M, Song J, Wong JR, Weiss MJ, Chen JB. Localization of endoplasmic reticulum in living and glutaraldehyde fixed cells with fluorescent dyes. Cell 1984;38:101-108. [PubMed: 6432338]

5. Petit JM, Maftah A, Ratinaud MH, Julien R. 10N-nonyl acridine orange interacts with cardiolipin and allows the quantification of this phospholipid in isolated mitochondria. Eur. J. Biochem 1992;209:267273. [PubMed: 1396703]

6. Morris RL, Azizuddin K, Lam M, Berlin J, Nieminen AL, Kenney MF, Samia AC, Burda C, Oleinick NL. Fluorescence resonance energy transfer reveals a binding site of a photosensitizer for photodynamic therapy. Cancer Res 2003;63:5194-5197. [PubMed: 14500343]

7. Lee C, Wu SS, Chen LB. Photosensitization by 3,3--dihexyloxacarbocyanine iodide: specific disruption of microtubules and inactivation of organelle motility. Cancer Res 1995;55:2063-2069. [PubMed: 7743503]

8. Berg K, Madslien K, Bommer JC, Oftebro R, Winkelman JW, Moan J. Light induced relocalization of sulfonated mesotetraphenylporphines in NHIK 3025 cells and effects of dose fractionation. Photochem Photobiol 1991;53:203-210. [PubMed: 2011624]

9. Kessel D. Relocalization of cationic porphyrins during photodynamic therapy. Photochem. Photobiol. Sci 2002;1:837-840. [PubMed: 12659521] 


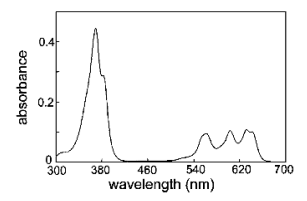

Figure 1.

Absorbance spectrum of CPO ( $3 \mu \mathrm{M}$ in ethanol). 


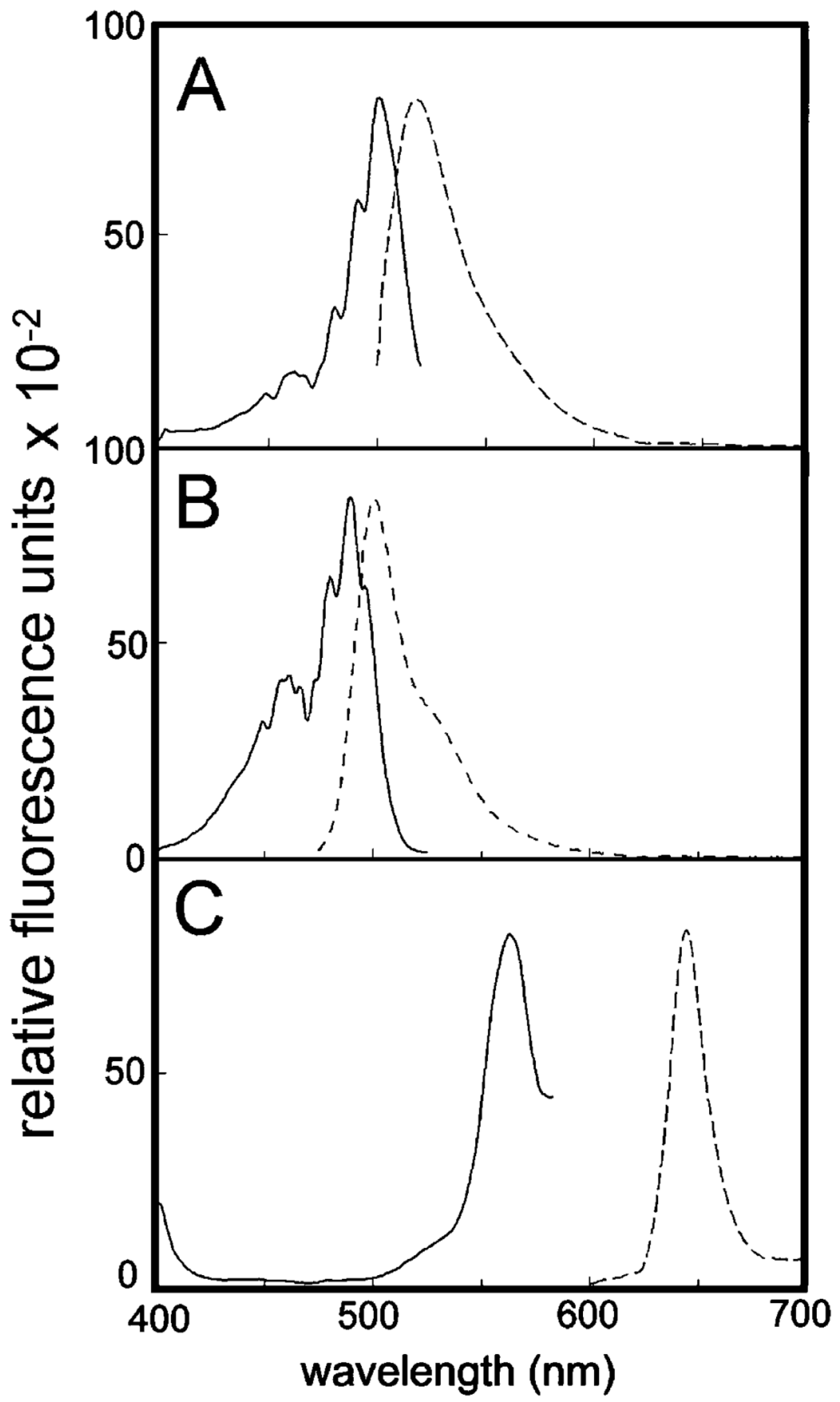

Figure 2.

Fluorescence emission and excitation spectra of $\mathrm{NAO}(\mathbf{A}) \operatorname{DiOC}_{6}(\mathbf{B})$ and $\mathrm{CPO}(\mathbf{C})$ in ethanolic solution. Solid lines $=$ excitation spectra, dashed lines $=$ emission spectra. 

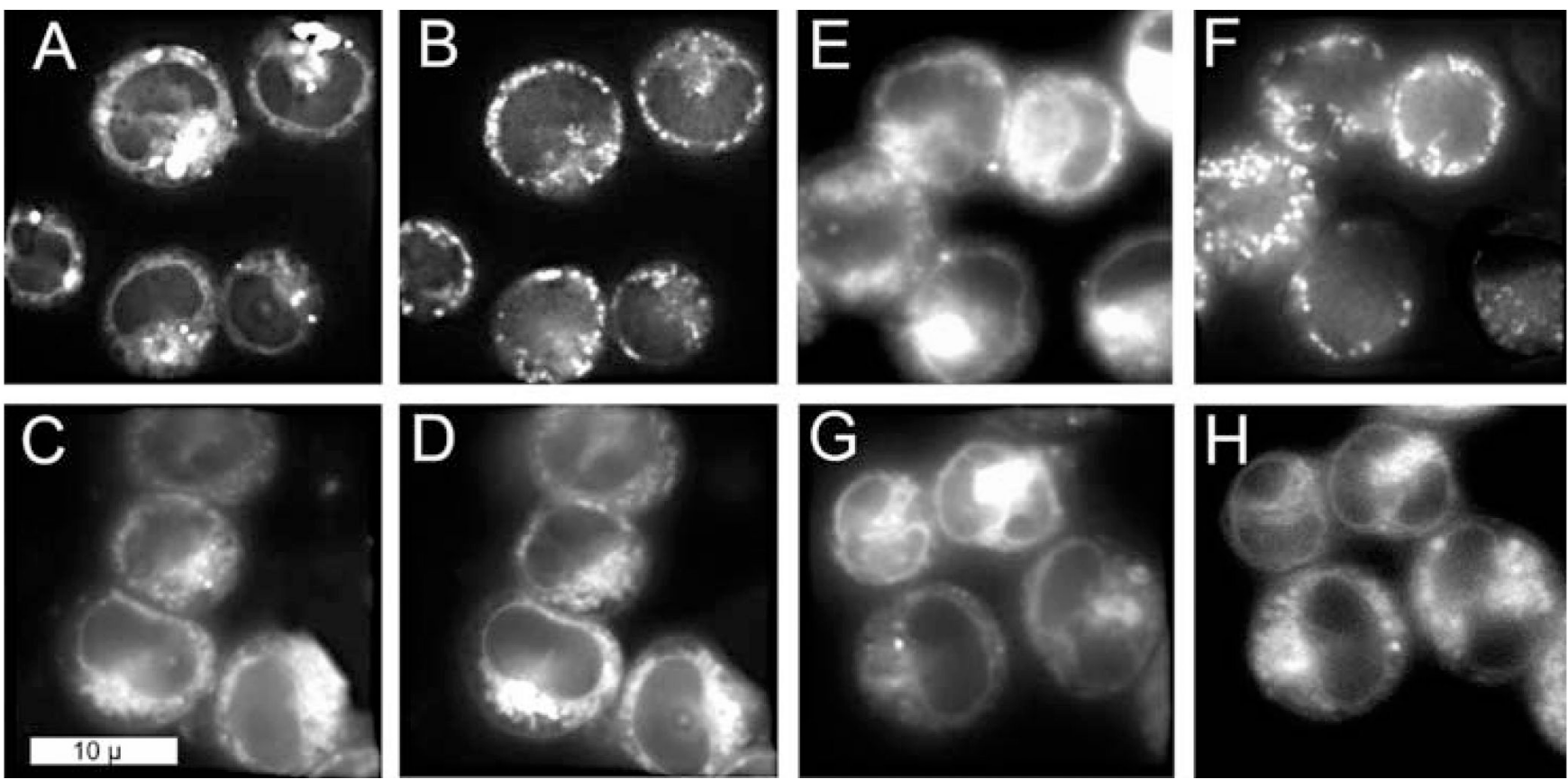

Figure 3 .

Fluorescence images of cells simultaneously loaded with two fluorophores. A-D. Before irradiation; E-H. After irradiation. A, E = CPO; B, F = NAO; C, G = CPO; D, H = $\mathrm{DiOC}_{6}$. Fluorescence emission signals were acquired at $600-700 \mathrm{~nm}(\mathrm{CPO})$ and $515-535 \mathrm{~nm}$ (NAO and $\mathrm{DiOC}_{6}$ ). 


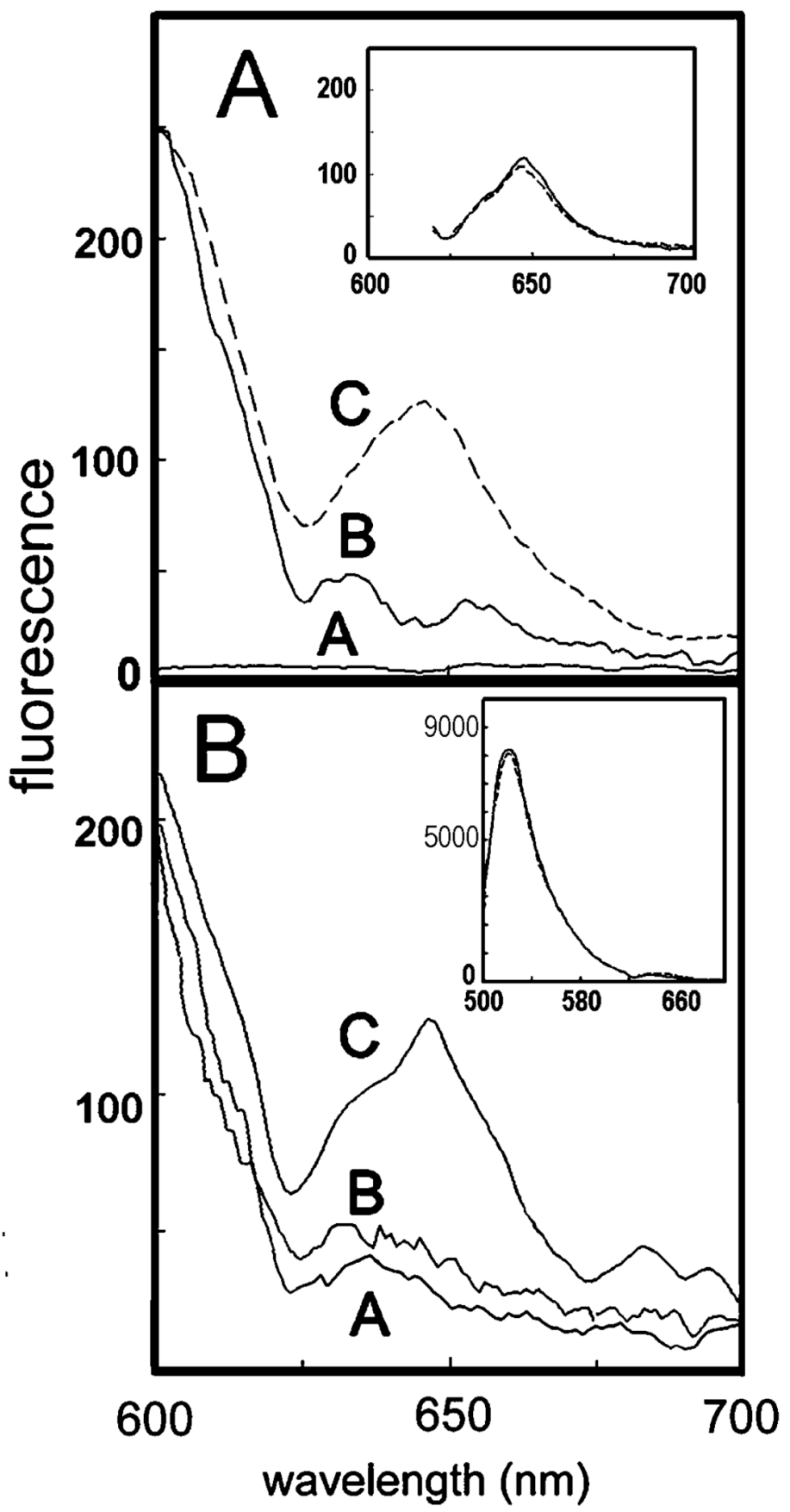

Figure 4.

Fluorescence emission spectrum of L1210 cell suspensions showing FRET between $\mathrm{CPO}$ and $\mathrm{DiOC}_{6}(\mathbf{A})$ and between $\mathrm{CPO}$ and $\mathrm{NAO}(\mathbf{B})$. In all cases, the excitation wavelength was 488 $\pm 2 \mathrm{~nm}$. Top: Trace $\mathrm{A}=\mathrm{CPO}$, trace $\mathrm{B}=\mathrm{DiOC}_{6}$, trace $\mathrm{C}=\mathrm{CPO}+\mathrm{DiOC}_{6}$. Inset: FRET between $\mathrm{DiOC}_{6}$ and $\mathrm{CPO}$ before (dashed line) and after (solid line) irradiation. Bottom: Trace $\mathrm{A}=$ $\mathrm{NAO}$ alone, trace $\mathrm{B}=\mathrm{NAO}+\mathrm{CPO}$ (no activation of $\mathrm{CPO}$ prior to $\mathrm{NAO}$ addition), trace $\mathrm{C}=$ $\mathrm{NAO}+\mathrm{CPO}$ (NAO added after PDT). Inset: The complete fluorescence emission spectrum for NAO in this experiment before (solid line) and after (dashed line) irradiation. 